\title{
LOS COLEGIOS RURALES AGRUPADOS, PRIMER PASO AL MUNDO DOCENTE
}

\author{
Ana Ponce de León Elizondo \\ Universidad de La Rioja \\ Enrique Bravo Sáinz \\ CRA San Vicente de la Sonsierra. La Rioja \\ Teresa Torroba Santa María \\ Universidad de La Rioja
}

RESUMEN. La constante búsqueda por mejorar la calidad de la educación en el medio rural ha provocado en los últimos años la aparición de los Colegios Rurales Agrupados -CRAs- en la práctica totalidad del territorio español.

Las especiales condiciones del medio rural exigen que la vida educativa de estas zonas se adapte a estas peculiaridades provocando una dinámica interna educativa bien diferente a la de otros centros.

Este artículo estudia y analiza las condiciones de creación, la organización, estructura y funcionamiento de estos centros partiendo del marco legal vigente que los sustenta hasta llegar a su contextualización en un CRA de la Comunidad Autónoma de La Rioja.

También se exponen unas serie de valoraciones respecto a este tipo de centros una vez transcurridos varios años desde su puesta en marcha.

El contenido del mismo pretende servir a la Formación Inicial del Profesorado de Primaria, ya que el primer destino para los maestros que optan profesionalmente por la función pública docente viene siendo, habitualmente, un Colegio Rural Agrupado.

ABSTRACT. The steadfast search for improving the quality of the education in the rural areas has led to the creation of the Rural Assembled Centres -CRAs- in recent years, practically all over the Spanish territory.

The special conditions of the rural areas demand the adaptation of the educative system to their peculiarities, as a result of it the internal educative organization is different to the other schools'.

This paper studies and analyses the conditions of their creation and explains the organization and functioning of these centres, starting from the current legal framework, which support them, to pay attention on the development of a Rural Assembled Centre in the Autonomic Community of La Rioja.

We also present, in this paper, some appraisals in relation to this kind of schools, once there have passed several years since their creation.

This study intends to be useful for the Initial Teacher Training, since the first appointment as a teacher will probably be a Rural Assembled Centre -CRA- if the would-be teacher professionally chooses to enter into the State School System. 


\section{Introducción}

Definimos Colegio Rural Agrupado -CRA- como la organización basada en la agrupación de varias unidades que constituyen un colegio y cuyo ámbito se extiende entre varias localidades.

Con la puesta en marcha de los CRAs en La Rioja, como en el resto de provincias, se pretendía conseguir una mejora significativa de la calidad de la enseñanza en el área rural, cimentada en los siguientes aspectos' ${ }^{1}$ :

- Mantener en funcionamiento las escuelas rurales, incluidas las unitarias.

- Garantizar que los alumnos se eduquen en su medio socio-familiar, puesto que son los maestros especialistas los que itineran por las distintas localidades del CRA.

- Dotar de profesorado especialista para que se impartan todas las materias marcadas en la LOGSE (idioma extranjero, educación física y música).

- Asegurar una enseñanza de calidad al mismo nivel que la de los centros urbanos, respetando las características de cada municipio.

- Incrementar los recursos humanos, económicos y didácticos de la escuela rural.

- Corregir el aislamiento del profesorado, potenciando la creación y desarrollo de equipos de profesores que trabajen coordinadamente en la elaboración y mejora de los Proyectos Educativos y Curriculares del centro.

La variación y dispersión del alumnado en distintas poblaciones hace que la organización de un Colegio de este tipo sea de tal complejidad que afecta a la composición de los Órganos de Gobierno y de Coordinación, al funcionamiento y organización de espacios, recursos materiales y humanos y, en definitiva, a la vida de la Comunidad Educativa.

\section{Origen y evolución de los Colegios Rurales Agrupados. Su presentación en la Comunidad Autónoma de La Rioja}

En el Real Decreto 2731/1986 de 24 de diciembre (BOE del 9 de enero), el Ministerio de Educación y Ciencia establecía por vez primera la posibilidad de constituir Colegios Rurales Agrupados de Educación General Básica. En él se hacían explícitos, entre otros, los siguientes puntos:

- En las zonas rurales, el MEC podrá acordar la agrupación de las unidades escolares existentes en una o varias localidades, con la finalidad de mejorar las condiciones y la calidad de la enseñanza en dichas zonas. (Apartado 1. Art.1ํ).

- Las unidades objeto de la agrupación se considerarán extinguidas como tales a partir del momento en que se constituya el Colegio Rural Agrupado. (Apartado 3. Art. $1 \%$ ).

1. Recogidos del Documento Colegios Rurales Agrupados, que la Unidad de Programas Educativos de la Dirección Provincial de Educación y Ciencia, en La Rioja, elaboró al respecto. 
- La constitución de los Colegios Rurales Agrupados se realizará de oficio, a propuesta de la correspondiente Dirección Provincial del MEC o a instancias del órgano competente de uno o varios de los centros preexistentes. En todo caso, será preceptiva la consulta a los padres de alumnos, profesores y Ayuntamientos implicados. (Apartado 1. Art. 4\%).

- Las propuestas o instancias deberán ir acompañadas de una memoria que incluirá, al menos, los aspectos siguientes: análisis de las condiciones geográficas de la zona afectada, razones o factores funcionales y pedagógicos que avalan la conveniencia de la agrupación y la relación detallada de las necesidades de profesorado, gastos de funcionamiento $y$, en su caso, de inversiones nuevas derivadas del proyecto. (Art. 5\%).

- Transcurridos tres cursos académicos desde la constitución del Colegio Rural Agrupado el MEC evaluará los resultados educativos obtenidos, pudiendo modificar, si las circunstancias lo aconsejan, la composición y características del mismo. Igualmente procederá la modificación cuando la alteración de las circunstancias iniciales así lo exija. (Art. 8º).

- Lo dispuesto en el presente Real Decreto no será de aplicación en las Comunidades Autónomas que, teniendo competencia en materia de enseñanza, hayan recibido los correspondientes traspasos de funciones y servicios. (Disposición Final Primera).

Posteriormente, en la ORDEN de 20 de julio de 1987 (BOE del 25) se perfilará más detalladamente el procedimiento a seguir para la constitución de Colegios Rurales Agrupados de Educación General Básica, estableciendo en el Artículo Segundo: "A los efectos previstos en el apartado anterior, se entenderá órgano competente de los centros preexistentes, el Claustro de Profesores de las unidades cuya agrupación se pretende". En el Artículo Tercero de la Orden, se cita la composición a la que debe atender toda propuesta o solicitud de constitución de un CRA.

De acuerdo a esta normativa comenzaron a originarse CRAs por los distintos ámbitos rurales del territorio nacional. Las provincias con mayores necesidades de atención a la enseñanza rural fueron las primeras en aventurar esta dinámica educativa.

En la Comunidad de La Rioja los seis primeros centros que funcionaron con estas características datan del curso 1993-94, a los que se sumaron cinco más en el siguiente curso 1994-95, quedando de esta forma configurada toda la zona con ámbito rural de La Rioja.

En el Gráfico 1 se observa que las localidades enmarcadas con trazo continuo, corresponden a los primeros CRAs, cuyas sedes fueron: San Vicente de la Sonsierra, Uruñuela, Torrecilla en Cameros, Quel, Igea y Cervera del Río Alhama. A ellos se unieron el curso siguiente los Centros Rurales Agrupados enmarcados con trazo discontinuo, representados por las sedes: Casalarreina, Agoncillo, Badarán, Ezcaray y Nalda.

Posteriormente estos centros han sufrido una serie de modificaciones al amparo del Real Decreto 82/1996, de 26 de enero (BOE del 2 de febrero), por el que se aprueba el Reglamento Orgánico de las Escuelas de Educación Infantil y de los Colegios de Educación Primaria. En el Artículo 3 sobre Modificación de la red de centros de educación infantil y primaria, podemos leer: 


\section{Gráfico 1. Los CRAs en La Rioja}

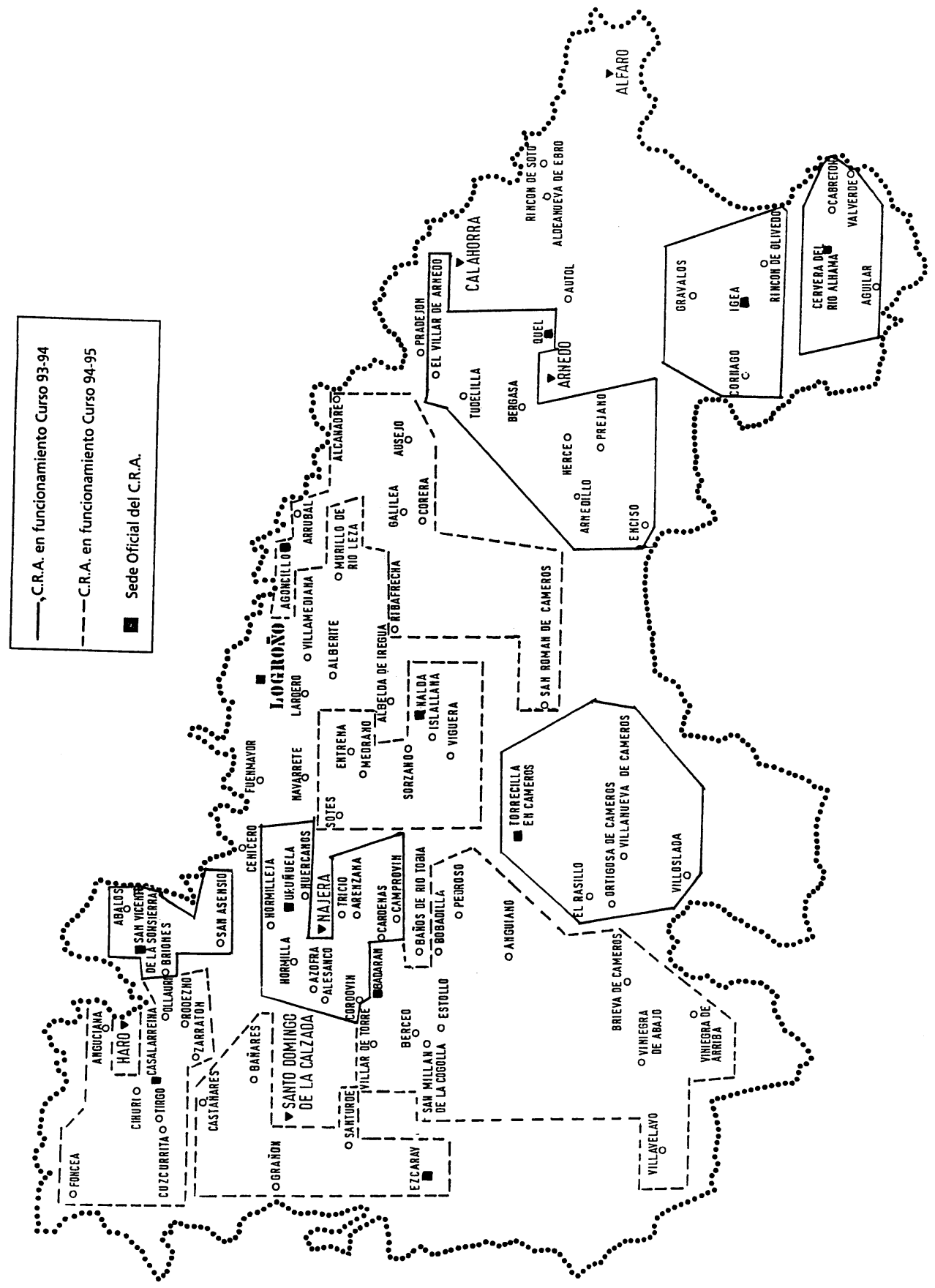


1. Por Orden del Ministerio de Educación y Ciencia podrá modificarse la red de centros existente en función de la planificación de la enseñanza.

2. El Ministerio de Educación y Ciencia podrá autorizar la creación o supresión de unidades de educación infantil o de educación primaria que se estimen necesarias para la atención de poblaciones con especiales características sociodemográficas o escolares.

3. El Ministerio de Educación y Ciencia podrá autorizar la agrupación de las unidades creadas, con arreglo a lo dispuesto en el apartado anterior de forma que entre ellas constituyan un Colegio Rural Agrupado, cuyo ámbito de actuación se extenderá a varias localidades.

El CRA San Vicente de la Sonsierra comenzó con las localidades actuales de San Vicente de la Sonsierra, Ábalos, Briones y San Asensio más las de Ollauri y Rodezno, las cuales fueron incorporadas al CRA de Casalarreina en el siguiente curso escolar. Hoy en día, una vez asumidas las competencias educativas en la mayoría de comunidades autónomas -en La Rioja desde el 1 de enero de 1999-, la Administración Educativa de esta provincia se plantea nuevamente la reestructuración de los Colegios Rurales Agrupados que se encuentran bajo su ámbito de actuación.

\section{Estructura de un CRA}

\subsection{La cabecera y las localidades del CRA}

Como se constata en el gráfico anterior, un Colegio Rural Agrupado se configura con la agrupación de varias unidades de localidades diferentes en torno a una sede visible ante la comunidad educativa escolar y denominada cabecera del CRA, pudiendo o no dar nombre a este Colegio. El actual CRA de la Cuenca del Najerilla no muestra el nombre de su cabecera, que es Uruñuela. Lo mismo ocurre con el reciente CRA de Moncalvillo, cuya cabecera es Nalda, mientras que el CRA de Igea o el de San Vicente de la Sonsierra, sí que se conocen por el mismo nombre.

En el momento de adjudicar el nombre a un CRA, será necesario atender al punto 4 del Artículo 4 sobre denominación de los centros, del Real Decreto 82/1996, anteriormente citado. En él podemos leer que los Colegios Rurales Agrupados tendrán la denominación específica que apruebe el Ministerio de Educación y Ciencia a propuesta del Consejo Escolar del colegio, previa consulta a los Ayuntamientos implicados.

La cabecera únicamente representa la referencia y sede administrativa, dando su dirección al CRA para la correspondencia y los documentos oficiales. No siempre coincide con el centro de mayor número de alumnado. El resto de localidades dependen de la cabecera en tanto sede administrativa, por eso hay CRAs que celebran los actos oficiales como reuniones, Consejos Escolares, Claustros, etc., en la sede y otros lo hacen en la localidad mejor situada o según el turno de localidades establecido previamente.

Sin embargo hay una labor manifiesta en torno a la sede del CRA como referencia administrativa que es. El Equipo Directivo desarrolla en ella la mayor parte de su tarea directiva, lo que hace que desde allí se gestione la vida cotidiana del resto de locali- 
dades en cuanto al reparto de información, archivo de documentos, datos informatizados del CRA, estadísticas, etc.

Todo ello pone al descubierto, desde nuestro punto de vista, una de las más grandes realidades de un CRA. Cada localidad tiene su profesorado, más o menos definitivo; cada localidad tiene su Ayuntamiento, con unas relaciones ya marcadas con las localidades vecinas; cada localidad tiene una Asociación de Padres de Alumnos -APA-, o incluso hay localidades que ni la tienen. Todo este personal e instituciones están obligados a funcionar conjuntamente para que la vida escolar vaya de la mano, porque a pesar de la diversificación, la escuela es una, única para esas localidades.

La necesidad de cambiar de mentalidad a todos estos elementos de la comunidad educativa para trabajar en torno a unos fines y objetivos comunes, es todavía hoy un punto crucial de los Colegios Rurales Agrupados.

¿Cómo funciona un CRA por dentro? ¿Cómo es la estructura interna que permite a una escuela rural contar con una educación satisfactoria? Dar respuesta a estas incógnitas es el cometido del próximo apartado.

\subsection{Los Órganos de Gobierno y de Coordinación de un CRA}

Otra peculiaridad cercana a los CRAs es su continua comparación con los centros urbanos, aunque la creemos fuera de lugar, puesto que las diferencias que puedan existir no surgen ni por los niños ni por los maestros ni por los padres y madres, si bien los contextos son muy diferentes. ¿Qué consecuencias se derivan de ello?

Un colegio Rural Agrupado tiene tantas características propias y únicas asociadas a su condición organizativa y estructural que necesita una normativa específica o la adaptación de la vigente. De hecho son cada vez más numerosos los artículos y normas legales que se destinan a regular el funcionamiento de los CRAs. Esa normativa ha de estar basada en la autonomía organizativa que cada centro debe tener en cuestiones de funcionamiento y en la validez de los acuerdos internos que giren en torno a sus Órganos de Gobierno y de Coordinación.

Veamos cual es esa realidad al hablar de estos órganos oficiales:

Órganos de Gobierno: $\quad$ Órganos Colegiados: Consejo Escolar y Claustro. Órganos Unipersonales: Equipo Directivo.

Órganos de Coordinación: Equipos de Ciclo/Comisión de Coordinación Pedagógica / Tutores.

\subsubsection{Los Órganos de Gobierno}

\section{EL CONSEJO ESCOLAR}

El Consejo Escolar es el Órgano de Gobierno encargado de velar por el correcto funcionamiento del centro y está compuesto por representantes de toda la comunidad educativa. Nos encontramos con maestros, padres y madres, personal del Ayuntamiento, personal de administración y servicios si lo hubiere y alumnos. El número de representantes de cada sector varía dependiendo del número de unidades del colegio. 
El Real Decreto 82/1996, citado anteriormente, señala que el Consejo Escolar de los centros que tengan nueve o más unidades, como es el caso de la mayoría de CRAs, estará compuesto por los siguientes miembros:

- El Director del centro, que será su presidente.

- El Jefe de Estudios.

- Cinco maestros elegidos por el Claustro.

- Cinco representantes de los padres de alumnos.

- Un representante del personal de administración y servicios.

- Un concejal o representante del Ayuntamiento.

- El Secretario, que actuará como Secretario del Consejo, con voz pero sin voto.

El número de miembros disminuye si el número de unidades del colegio es menor, mas siempre con la premisa de estar representados los diferentes miembros de la comunidad educativa.

Los representantes de los maestros en el Consejo Escolar son elegidos en reunión extraordinaria de Claustro. La Resolución 3303 de 19 de octubre de 1999 (Boletín Oficial de La Rioja -BOR- del 18 de noviembre), por la que se dictan las instrucciones para la renovación o, en su caso, elección y constitución de los Consejos Escolares de los colegios públicos de Educación Infantil y Educación Primaria de la Comunidad Autónoma de La Rioja, en el punto 4 del Capítulo Décimo sobre la elección de los representantes de los profesores, apunta que, los maestros itinerantes que impartan docencia en dos o más centros, tienen derecho a ser electores y elegidos únicamente en el centro que tengan su destino o, si carecen de él, en el que tengan mayor carga lectiva.

En cuanto a los padres, son electores y elegibles todos los padres o tutores legales de los alumnos que estén matriculados en el centro. La elección se produce entre las personas que previamente presentaron su candidatura a representantes de los padres en el Consejo Escolar.

El representante del personal de administración y servicios es elegido por el personal que realice en el centro funciones de esta índole, siempre que esté vinculado al mismo, o al Ayuntamiento correspondiente, por relación jurídico administrativa o laboral. Generalmente, en el Consejo Escolar de los CRAs esta representación queda vacante.

En el caso de los Colegios Rurales Agrupados, la representación municipal es ostentada cada año académico por uno de los Ayuntamientos a los que la agrupación extienda su ámbito de influencia. El representante municipal está obligado a informar a todos los Ayuntamientos de las localidades del CRA, de los asuntos tratados y de las decisiones adoptadas por el Consejo Escolar.

Los alumnos pueden estar representados en el Consejo Escolar del colegio con voz pero sin voto, de acuerdo a lo que se haya acordado y figure en el Proyecto Educativo del Centro. Esta representación también suele quedar vacante debido a la corta edad de los educandos.

El Consejo Escolar se renueva por mitades cada dos años de forma alternativa. Cada una de ellas estará formada, en los centros que tengan nueve o más unidades, por tres maestros y dos padres de alumnos (primera mitad) y los restantes maestros y represen- 
tantes de los padres de alumnos y los representantes del personal de administración y servicios (segunda mitad). La configuración disminuye paralelamente a la disminución del número de unidades de los centros, como ya se advirtió anteriormente.

Las reuniones del Consejo Escolar se han de celebrar en el día y con el horario que posibiliten la asistencia de todos sus miembros. Como mínimo, se reúne una vez al trimestre y será necesaria, en todo caso, una reunión a principio de curso y otra al final del mismo. En un CRA, las reuniones se realizan en la sede, donde se centraliza toda la documentación objeto de revisión por el Consejo Escolar y por las diferentes Comisiones que este órgano genera, relativas a asuntos económicos y de convivencia principalmente.

En los Colegios Rurales Agrupados la normativa queda adaptada a las peculiaridades concretas de este tipo de centros, de manera que, en el caso del Consejo Escolar, lo más significativo es intentar conseguir un equilibrio en la representación de las distintas localidades que lo forman.

\section{Gráfico 2. Renovaciones parciales del Consejo Escolar}

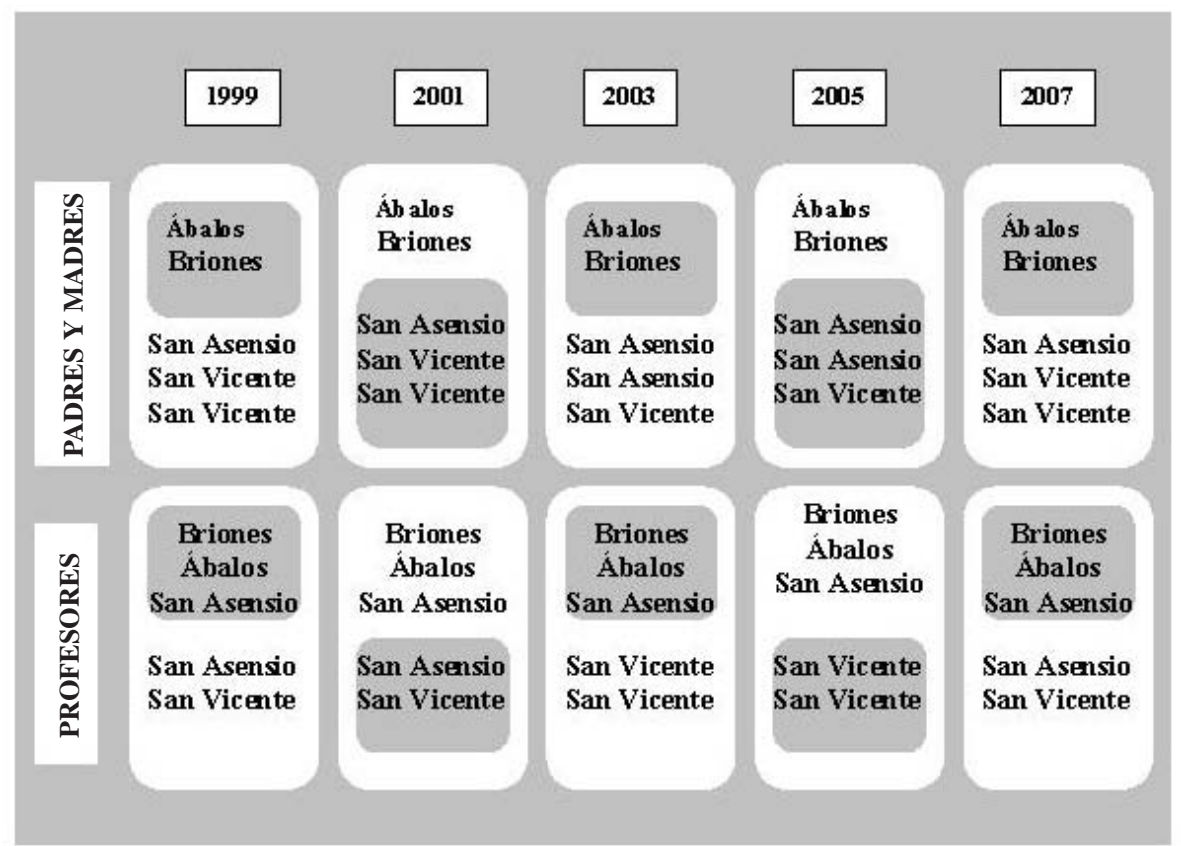

En el CRA San Vicente de la Sonsierra, concretamente, como muestra el gráfico, con la intención de contar con representantes de cada localidad del CRA, tanto en el sector profesores como padres, se ha establecido un convenio de renovaciones parciales cada dos años, como marca la ley, de manera que siempre exista una compensación en el número de representantes de ambos sectores, por cada localidad del centro. Las localidades encasilladas en cada uno de los años que corresponde reno- 
var a los miembros del Consejo, indican los representantes objeto de cambio. De esta manera queda organizado el Consejo Escolar hasta el año 2007. A partir de esta fecha comenzaría de nuevo el turno marcado en el año 1999. Con ello conseguimos que Ábalos, Briones, San Asensio y San Vicente queden suficientemente representados de acuerdo al número de alumnos de cada escuela. Esta circunstancia es soberanamente agradecida en las reuniones de Consejo, ya que cualquier tema de una localidad es tratado con la suficiente seriedad al contar con las opiniones involucradas, algo que sería imposible si alguna localidad del CRA no tuviera representación en este órgano, lo que ocurre en Colegios Rurales Agrupados de numerosas localidades, en donde existe el inconveniente de no poder tratar un tema con las personas que representan a la localidad en donde se produce.

Para finalizar con este elemento, diremos que en las sesiones de Consejo se observa la necesidad de considerar todos los temas con mentalidad conjunta de escuela única. Todos sus miembros han de ser especialmente sensibles a este punto y comprender su importancia. Es por ello que se intenta, de la forma más precisa, que todas las localidades tengan presencia equilibrada.

\section{CLAUSTRO DE PROFESORES}

El Claustro de Profesores es el órgano propio de participación de los maestros en el centro y tiene la responsabilidad de planificar, coordinar, decidir e informar sobre todos los aspectos docentes del mismo. Es presidido por el Director y está integrado por la totalidad de los maestros que prestan servicios en el colegio.

\section{Gráfico 3. Claustro de Profesores}

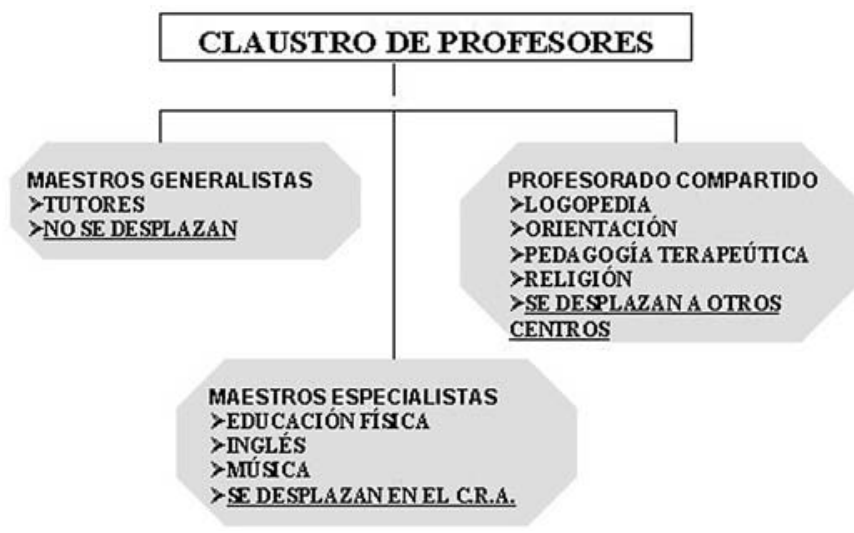

En un CRA, el Claustro estará compuesto por:

1. Maestros generalistas: aquellos que no imparten especialidades, sino que se dedican a la enseñanza de todas las materias propias de Educación Infantil y Pri- 
maria, a excepción de las especialidades. Son fijos, no itineran de una a otra localidad del CRA. Son tutores de un grupo de alumnos.

2. Maestros especialistas: imparten las especialidades de Educación Física, Música e Inglés. La mayoría son itinerantes, es decir, recorren localidades del centro, a excepción de quienes desempeñan toda su labor en una única localidad, que generalmente son tutores.

3. Profesorado compartido: logopedas, orientadores, especialistas en Pedagogía Terapéutica y Religión. No dedican su jornada en exclusiva al CRA, sino que la reparten entre otros CRAs o centros de la zona. Por su condición, todos son itinerantes.

Se hace necesario hablar ahora de la aparición en los CRAs del maestro itinerante. Debido a la estructuración e idea por la que fueron creados estos colegios (que cada niño permanezca en su localidad recibiendo enseñanza), serán los maestros quienes se desplacen a las localidades a impartir docencia. Corresponde al profesorado especialista la condición de itinerante. Estos maestros imparten docencia moviéndose de una localidad a otra a lo largo de la jornada escolar, por lo que no suelen ser tutores, a no ser que las condiciones educativas de un colegio del CRA así lo exijan. Su itinerancia es computada dentro del horario lectivo de trabajo que han de realizar y por ello el maestro itinerante dispone de una compensación horaria de acuerdo al número de kilómetros que obligan sus desplazamientos. Existe una tabla específica para estos casos que marca la compensación de horario lectivo en función de los kilómetros realizados para ir de una a otra localidad a impartir las sesiones de la especialidad.

El Claustro, con itinerantes, generalistas y compartidos, desarrolla su labor distribuido en las diferentes localidades.

Los órganos unipersonales de gobierno constituyen el Equipo Directivo del centro y trabajan de forma coordinada en el desempeño de sus funciones.

En los centros de nueve o más unidades, la composición del Equipo Directivo está formada por el Director, el Secretario y el Jefe de Estudios. Los miembros de este Equipo disminuyen en los colegios de menos unidades.

Los maestros que forman el Equipo Directivo pueden ejercer su función docente en cualquier localidad de las que configuran el CRA, si bien es muy aconsejable que la dirección y la secretaría estén juntas.

Las tareas del Equipo Directivo se realizan generalmente en la cabecera y sede administrativa, por lo que la elaboración del horario del centro ha de posibilitar a los componentes del Equipo la coincidencia de los días dedicados a funciones directivas en la localidad cabecera del CRA. Este aspecto será tratado más adelante.

Una función admitida por los miembros del Equipo Directivo y por los maestros itinerantes es que son los elementos de contacto y transporte en el CRA. Gracias a ellos, no solo las noticias, la correspondencia y el material son distribuidos por cada localidad, sino que, además, estos docentes suelen ser los que más desarrollan la mentalidad de Colegio Rural Agrupado, al tener que desplazarse y estar en contacto 
con la realidad de cada localidad y con el resto de compañeros. Ello se hace necesario a la hora de tomar decisiones que afecten a todo el CRA.

\subsubsection{Los Órganos de Coordinación Docente}

En los colegios con doce o más unidades, existen los siguientes órganos de coordinación docente: Equipos de Ciclo, Comisión de Coordinación Pedagógica y Tutores.

En los centros con menos de doce unidades, las funciones de la Comisión de Coordinación Pedagógica - $\mathrm{CCP}-$, son asumidas por el Claustro de Profesores. En todos los centros, independientemente del número de unidades, hay un maestro tutor por cada grupo de alumnos.

En la Orden de 29 de febrero de 1996 (BOE del 9 de marzo), por las que se aprueban las Instrucciones que regulan la Organización y Funcionamiento de las Escuelas de Educación Infantil y Colegios de Educación Primaria y de los Institutos de Educación Secundaria, el punto 96 del Apartado VII de estas instrucciones, sobre Colegios Rurales Agrupados, recoge una de las características más significativas en cuanto a la coordinación docente en los CRAs. Este punto informa que debe establecerse una reunión de coordinación, al menos quincenal, en la cabecera del colegio o en aquella localidad que sea de más fácil acceso para el equipo de maestros o, en último término, según disponga el Claustro. En el CRA San Vicente de la Sonsierra, se aprobó en Claustro celebrar las reuniones de coordinación rotando quincenalmente por cada una de las localidades del colegio -excepto Ábalos, porque la escuela es demasiado pequeña para acoger al número de maestros-. Más adelante veremos cómo afecta esta circunstancia al horario general del centro, ya que los niños no acuden a la escuela durante la realización de estas sesiones, por lo que habrá que recuperar el tiempo en el horario lectivo diario.

Existen CRAs que solicitan a la Administración de Educación, permiso para realizar las reuniones semanalmente, postura que, en opinión de muchos docentes, es la más acertada para una óptima y eficaz coordinación entre los maestros de este tipo de colegios. Son muchos los temas a tratar en el Claustro, las experiencias a compartir, las consultas que hacer, los trabajos que asumir en grupo y las tareas propias de coordinación, que se quedan excesivamente cortas las dos horas quincenales, aproximadamente, que los CRAs dedican a coordinarse. Estas reuniones semanales constituyen una alternativa eficaz y viable, siempre que el equipo de maestros se muestre dispuesto.

¿Cómo se organizan los educadores en estas reuniones? ¿Cuál es el trabajo que se realiza durante las sesiones de coordinación?

Los Equipos de Ciclo, que agrupan a todos los maestros que imparten docencia en él, son los órganos básicos encargados de organizar y desarrollar las enseñanzas propias del ciclo. Cada uno de los Equipos de Ciclo está dirigido por un Coordinador que anima y organiza el trabajo que se crea entre los miembros del grupo. En cada reunión de coordinación, quincenal o semanal, los maestros del equipo desarrollan las tareas que hayan acordado al comienzo de curso, o bien aquellas que vayan surgiendo a lo largo del mismo.

Los CRAs tuvieron que dedicar las sesiones de coordinación de los primeros años de su andadura a la elaboración de todos los documentos oficiales que un nuevo cen- 
tro escolar requiere. Por tratarse de un colegio de nueva creación, un CRA dispone de un período de tres cursos académicos para realizar el Proyecto Educativo de Centro -PEC-. En el caso del Proyecto Curricular -PC- de etapa, se contempla que cuando se elabore por vez primera, habrá que ajustarse a las indicaciones y plazos que la Secretaría del Estado de Educación haya establecido. La confección de estos documentos habrán de tener en cuenta que todos los maestros del Colegio Rural Agrupado forman parte de un único centro, con un Claustro, un Equipo Directivo, una sola Programación General Anual, un solo Proyecto Educativo de Centro y un solo Proyecto Curricular para cada etapa, tal y como se anuncia en el punto 95 de las Instrucciones Reguladoras de la Orden de 29 de febrero de 1996.

En los CRAs que ya han presentado oficialmente estos documentos, cada Equipo de Ciclo tiene la posibilidad de formar un Grupo de Trabajo, dependiente del Centro de Profesores y Recursos de la zona -CPR-, de tal manera que recibe su apoyo en la elaboración de materiales y experiencias.

Cuando los maestros del mismo ciclo se reúnen después de numerosos días sin haberse comunicado, la coordinación docente puede quedar afectada si los maestros tienden a asumir su pertenencia a un colegio determinado. De nuevo, la mentalidad de funcionamiento conjunto, de colegio único, ha de volverse a reforzar en estas ocasiones. El trabajo en equipo de los CRAs requiere tener siempre presente la idea de unidad educativa. Por ello estas oportunidades resultan muy necesarias para la comunicación entre maestros, para la apertura mental a nuevas sugerencias educativas y para evitar la soledad del trabajo individual.

La Comisión de Coordinación Pedagógica - CCP-de un CRA esta integrada por el Director, el Jefe de estudios, los Coordinadores de ciclo y, en su caso, el maestro orientador del centro o un miembro del equipo para la orientación e intervención educativa que corresponda a ese centro.

De las competencias que este órgano de coordinación asume, destacan las de establecer las directrices generales para la elaboración de los Proyectos Curriculares de etapa, elaborar la propuesta de organización de la orientación educativa y del plan de acción tutorial, proponer criterios y procedimientos para realizar las adaptaciones curriculares de los alumnos, presentar al Claustro la planificación de las sesiones de evaluación, así como el plan para evaluar el Proyecto Curricular de cada etapa, los aspectos docentes del Proyecto Educativo y la Programación General Anual y, por último, impulsar planes de mejora en el centro en caso de que se estime necesario.

Como ocurre en el CRA San Vicente de la Sonsierra, y también en otros Colegios Rurales Agrupados, la mayor parte de estas funciones son asumidas por el Equipo Directivo y los maestros del CRA, debido a la falta de tiempo real para realizar un seguimiento adecuado de los acuerdos tomados en las reuniones mensuales de la CCP Es el Equipo Directivo quien visita cada centro del CRA y se reúne, en distintos días, con los Coordinadores de ciclo y con el maestro o especialista orientador; de esta manera recoge las sugerencias de todas esas personas y propone la línea de actuación a seguir.

El maestro especialista en Pedagogía Terapéutica, si lo hubiese, se involucra también en estas labores. 
Como característica intrínseca a los CRAs, se hace necesario añadir que pocos son los que tienen servicio de comedor. La permanencia de los alumnos en la localidad permite que todos ellos vayan a sus casas a comer. Los maestros, por su parte, al ser escaso el número que vive en la localidad donde imparte docencia, han de comer en el propio centro escolar o en establecimientos apropiados. El tiempo dedicado a la comida también sirve como complemento a la coordinación y mantenimiento de la armonía entre todos los maestros de la localidad.

Al hablar de los aspectos coordinativos de un CRA, estamos poniendo al descubierto, a nuestro juicio, una de las características más deficiente de estos centros, en comparación con otros colegios, generalmente urbanos, en donde la coordinación es más continua y cercana. En los Colegios Rurales Agrupados se han de hacer importantes esfuerzos para que la coordinación docente sea eficaz, y no siempre es posible.

¿Cómo se organiza un CRA? ¿Cuáles son sus relaciones internas y externas? ¿Qué recursos le permiten funcionar? Descubramos en el siguiente apartado la peculiar vida organizativa que posibilita una óptima educación en el medio rural.

\section{Organización de un CRA}

\subsection{Alumnado y distribución}

El Artículo 47 del Capítulo I del Título IV sobre Autonomía de los Centros, del Real Decreto 82/1996 ya referido, expresa que "Los centros dispondrán de autonomía para definir el modelo de gestión organizativa y pedagógica, que deberá concretarse, en cada caso, mediante los correspondientes proyectos educativos, curriculares y de sus respectivos reglamentos de régimen interior". Este contenido es de gran importancia para los Colegios Rurales Agrupados.

Un CRA cuenta con los alumnos matriculados en cada una de las localidades que lo forman. Esos alumnos asisten únicamente al colegio ubicado en su localidad. A cada colegio del CRA le corresponde un número determinado de maestros proporcional al número de alumnos que estudian en ese centro. Teniendo en cuenta ambos elementos, alumnado y maestros, se organizan los agrupamientos.

Los criterios que determinan los agrupamientos en un CRA son dos básicamente: el número de niños por aula y el no separar ciclos (siempre que exista la posibilidad).

Surge así una de las características más evidentes de un CRA, las aulas mixtas, formadas por alumnos de niveles diferentes de Educación Infantil y Primaria. Dependerá del número de alumnos y maestros el que esas aulas mixtas acojan diferentes niveles o, lo que es lo mismo, la unión de niños de diferentes edades. En localidades de suficiente alumnado, generalmente, encontraremos aulas mixtas formadas por ciclos completos: los tres ciclos de Educación Infantil en una aula y primer, segundo y tercer ciclos de educación primaria en aulas diferenciadas, una para cada ciclo. Éste sería un ventajoso agrupamiento, difícil de encontrar y de agradable desenvolvimiento para los maestros.

A medida que el número de alumnos desciende en las localidades, también existen menos maestros asignados en esa localidad dando lugar a aulas donde conviven dife- 
rentes ciclos de Educación Primaria juntos, aumentando todavía más la dificultad educativa cuando ha de mezclarse alumnado de infantil y primaria, hasta llegar a las conocidas escuelas unitarias, con una única aula que acoge a todos los niños matriculados, tengan la edad que tengan y pertenezcan a uno u otro ciclo de Educación Infantil y Educación Primaria. En estas escuelas puede darse el caso, abundante en los Colegios Rurales Agrupados, de encontrar a niños de tres años y otros de once compartiendo enseñanza, aula y maestro. Aún así, estos agrupamientos no alcanzan nunca un número elevado de alumnos por aula y profesor. A pesar de juntar a todos los niveles de Educación Infantil y Primaria, el aula no suele contar con más de diecisiete alumnos, siendo más frecuente encontrarnos con aulas de cinco, seis o siete educandos.

Otra peculiaridad del medio rural es el alumnado temporero. Pertenecen a familias cuyos miembros son trabajadores que se desplazan de acuerdo a exigencias laborales temporales. Familias que viven por un tiempo en una zona y cambian de lugar dependiendo de dónde puedan trabajar. En nuestra provincia es predominante esta población temporera itinerante en época de vendimias, recolección de la patata, fruta, etc. A estos niños y niñas la escuela debe atenderlos, los matricula en el centro y los integra en el grupo correspondiente, pasando a ser considerados como alumnos del CRA, a todos los efectos, durante el tiempo que allí estudian.

Para estos casos existen unas "Cartillas de seguimiento" si los niños se quedan menos de tres meses en el centro. En este documento se recoge el progreso del alumno y se envía a la Administración Educativa correspondiente para que ésta lo remita al centro de procedencia. En el caso de que el alumno matriculado vaya a permanecer por un período de tiempo superior a los tres meses, se formaliza la matrícula y se pide la documentación oficial relativa del alumno al centro de procedencia.

\subsection{Profesorado y establecimiento en las diferentes localidades que forman el CRA}

Una vez estudiado el alumnado de los CRAs, expondremos la manera cómo los maestros eligen el lugar donde impartirán docencia dentro del ámbito del colegio. Se atiende, fundamentalmente, a los criterios que se corresponden con las Instrucciones que regulan la Organización y el Funcionamiento de las Escuelas y Colegios de Educación Infantil y Primaria, respectivamente (Orden de 29 de febrero de 1996, BOE del 9 de marzo):

- La asignación de ciclos, cursos, áreas y actividades docentes se ha de realizar en base a:

- la permanencia de un maestro con el mismo grupo de alumnos hasta finalizar el ciclo.

- la especialidad del puesto de trabajo al que esté adscrito cada maestro.

- otras especialidades para las que el maestro esté habilitado. (Punto 73).

- En los Colegios Rurales Agrupados, esta asignación se realiza por el Director, de acuerdo con la normativa existente al respecto y teniendo en cuenta las peculiaridades organizativas de estos centros. No obstante lo anterior, los maestros procedentes de centros o unidades integrados en un CRA, tienen preferencia para desempeñar sus funciones en la localidad donde trabajaban con anteriori- 
dad, siempre que esos maestros reúnan las condiciones correspondientes para cubrir la especialidad requerida en la misma localidad. (Punto 99).

Este sistema de elección permite a los maestros estabilizarse con el paso de los años en una misma localidad, de manera que la vida educativa gana solidez y consistencia al ir contando, año tras año, con el mismo equipo de maestros en la misma escuela. Lógicamente este dato contribuye a que la enseñanza mejore su calidad y que la relación con los restantes miembros de la comunidad educativa sea más enriquecedora. Esta es, de nuevo, una característica importante de los CRAs. A medida que el profesorado se estabiliza en las localidades, se observa un ambiente educativo diferente al que se consigue en el ir y venir de maestros provisionales. Por ello, en los distintos colegios es de agradecer la estabilidad del profesorado, que se irá consiguiendo en la medida que éstos se conviertan en propietarios definitivos de sus plazas.

Con relación a este tema, significar que un CRA vive intensamente la posibilidad de las supresiones del profesorado. Cada vez existen menos matrimonios jóvenes en los pueblos, por lo que el número de niños en edad escolar también disminuye progresivamente. Este dato desencadena el triste cierre de escuelas del medio rural. En La Rioja, localidades como Ollauri, Hormilleja o Berceo, vieron como sus escuelas desaparecían por falta de niños. Esa es una de las realidades más tristes de los centros rurales.

Hemos visto en este apartado los diferentes modelos de alumnado y profesorado que integran la escuela rural, vayamos ahora a conocer de qué manera se distribuyen los tiempos en estos centros.

\subsection{Distribución de los tiempos en un CRA. Los horarios}

Hablaremos en primer lugar del funcionamiento de un Colegio Rural Agrupado en su actuación particular a la hora de distribuir los tiempos.

El punto 53 del Apartado III de las Instrucciones Reguladoras de las Escuelas y Colegios -Orden de 29 de febrero de 1996, (BOE del 9 de marzo)- señala que el Equipo Directivo, habiendo consultado al Claustro y atendiendo a las particularidades de cada centro y al mejor aprovechamiento de las actividades docentes, ha de presentar al Consejo Escolar, para su aprobación, la distribución de la jornada escolar y el horario general del colegio. En las mismas Instrucciones, el Apartado VII sobre Colegios Rurales Agrupados, recoge que el horario semanal de actividades lectivas se puede organizar en cinco períodos de mañana y cuatro de tarde, que sumen en total veinticinco horas. La tarde disponible se dedica a reuniones de coordinación.

De acuerdo con ello, en un CRA de la Comunidad riojana la jornada de mañana, de lunes a viernes, comienza, por lo general, más tarde de las nueve. Esta hora de entrada es una característica similar a la mayoría de los CRAs, seguramente debida a que el profesorado vive fuera de la localidad y ha de desplazarse hasta ella y porque la distribución horaria de los tiempos durante el día, para los niños, es más proporcionada.

La jornada de mañana termina a las 13 horas aproximadamente. La hora de obligada permanencia en el centro, conocida como exclusiva, se realizará de 13 a 14 horas. 
Gráfico 4. Plantilla de horarios C.R.A.

\section{HORARIO ANUAL DE UN COLRGIO RURAL AGRUPADO COMPUESTO POR 4 LOCALIDADES Y 14 DNIDADES. LOCALIDADES: A B C D}

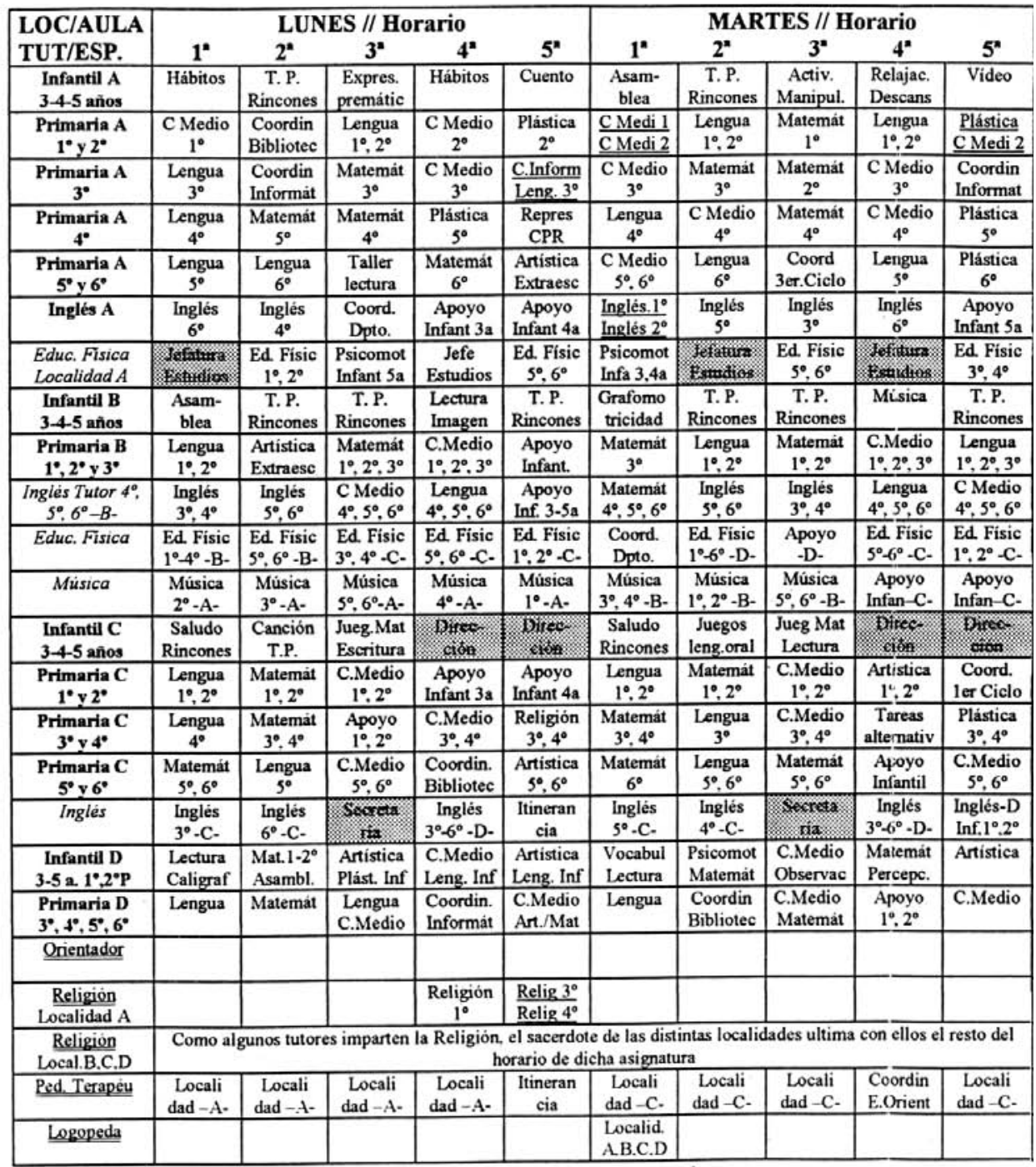

LEYENDA Las palabras subrayadas equivalen a desdobles

[3a] 3 años

[Activ. Manipul.] Actividades manipulativas [C.M.][C.Medio] Conocimiento del Medio

[Comp] Comprensión

[Dpto.] Departamento

[Escrit] Escritura [4a] 4 años

[Asam] Asamblea

[Centro Inter] Centro de interes

[Coord.] Coordinación

[E.F.] Educación Fisica

[Extraesc] Extraescolar
[Sa] 5 años

[Bibl][Bibliotec] Biblioteca

[D.Ext] Deporte Extraescolar

[E.Orient.] Equipo de orientación [Inf]|Infant| Infantil 


\section{MAESTROS GENERALISTAS (en letra negrita) MAESTROS ESPECLALISTAS ITIERANTES (en letra cursiva) MAESTROS COMPARTIDOS (co letra con doble subrayado)}

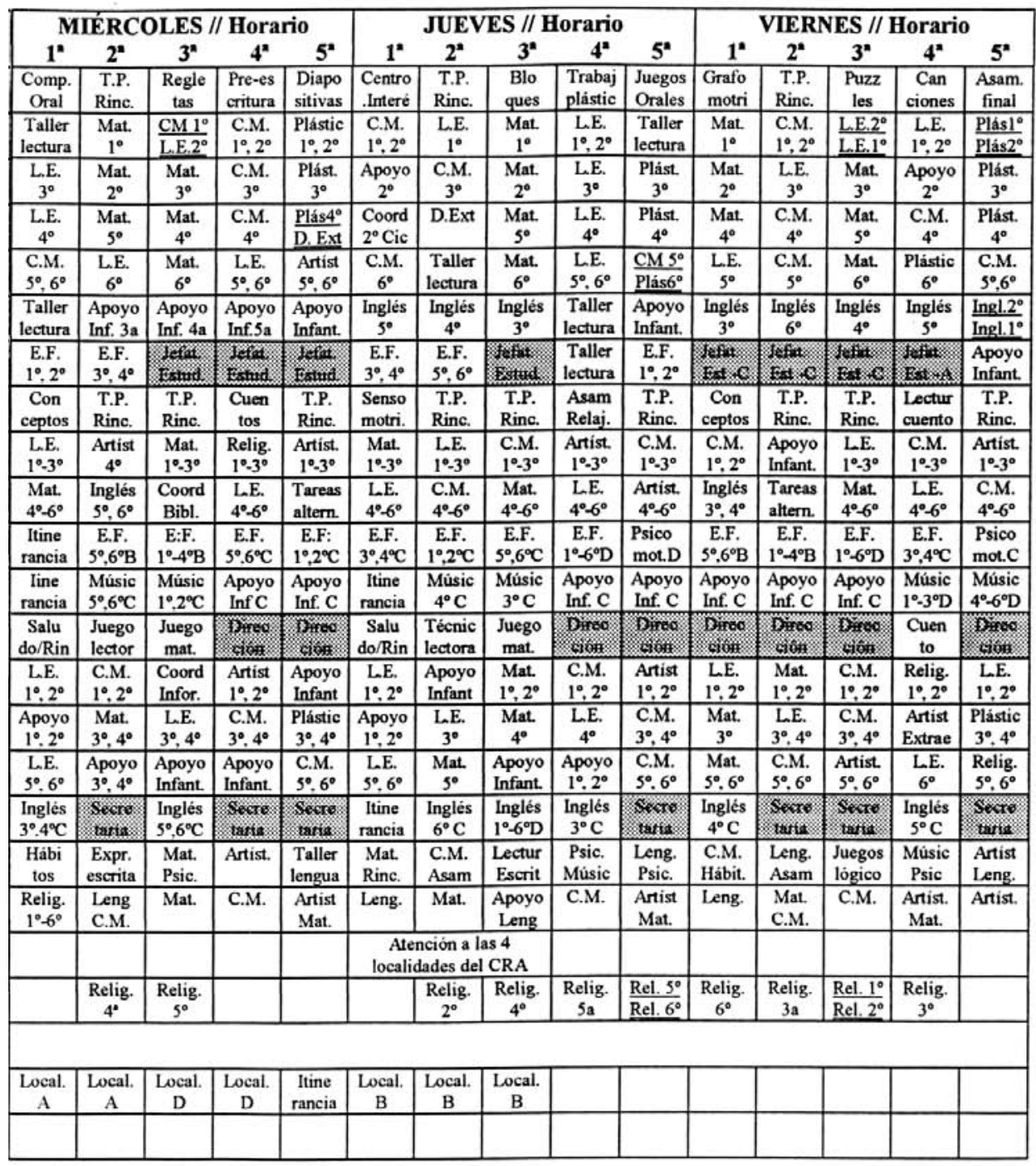

[Informát][Infor] Informática

[L.E.][Leng] Lengua

[Mat.] Matematicas

[Percepc.] Percepciones

[Relig][Rel.] Religión

[T.P.] Trabajo personal
LEYENDA Las palabras subrayadas equrvalen a desdobles [Jefat. Est] Jefatura de Estudios [Jueg.] Juegos
[Lectur] Lectura
[Local.]Localid.] Localidades
[Observac] Observaciones
[Plást][Plàs] Plástica
[Rinc.][Rin] Rincones

[Vocabul.] Vocabulario 
La jornada de tarde comienza, mayoritariamente, a las 15 horas y termina a las 16 horas 30 minutos ó 16 horas 40 minutos aproximadamente, dependiendo de la hora de entrada en la mañana.

Este horario se dispone así debido a lo ya comentado sobre la tarde quincenal que ha de dedicarse a la coordinación del profesorado, siendo necesaria la recuperación de este tiempo en el horario lectivo de cada día.

Tras observar la distribución de los tiempos, entramos de lleno en la confección de

\section{los horarios de un CRA.}

Diremos que éste es uno de los momentos más complicados en la tarea del Equipo Directivo, ya que se intenta facilitar al máximo la tarea educativa de todos los maestros a la vez que lograr la mejor estructura posible en la secuencia horaria de las asignaturas para los niños y niñas del colegio. Aquí confluyen numerosas circunstancias: normativa especial para itinerantes, número de maestros por localidad, número de alumnos por grupo y coordinación con la jornada de los maestros compartidos.

Observando el gráfico 4, conozcamos todos y cada uno de los pasos que se lleva a cabo en la tarea de confección del horario general del CRA San Vicente de la Sonsierra:

a) Primero se configura el horario de los maestros itinerantes, de manera que se respeta la normativa existente al respecto y que podemos encontrar en el Apartado VII de las Instrucciones Reguladoras a las que continuamente nos hemos venido refiriendo (Orden de 29 de febrero de 1996, BOE del 9 de marzo):

- La elaboración del horario lectivo del centro y la programación de sus actividades ha de prever el menor número posible de desplazamientos de los maestros itinerantes. Todos los desplazamientos necesarios, siempre que sea posible, han de efectuarse para impartir docencia en sesiones completas de mañana o de tarde. (Punto 98).

- La jornada lectiva de los maestros itinerantes comienza en la localidad del CRA donde impartan la primera sesión indicada en el horario de cada uno de ellos. La ruta de itinerancia se ha de realizar desde la localidad más alejada a la más próxima, de forma sucesiva, buscando la racionalidad en los desplazamientos. (Punto 100).

- Dadas las características de un CRA y la necesidad de que los maestros itinerantes se desplacen por diferentes localidades a lo largo de la jornada escolar, éstos quedan liberados de la atención de los alumnos en los períodos de recreo, siendo los maestros no itinerantes los encargados de esta función. (Punto 101).

- Los maestros itinerantes, procedentes de centros o unidades integrados en un Colegio Rural Agrupado, tienen preferencia para que sus rutas de itinerancia incluyan la localidad en la que anteriormente prestaban servicios. (Punto 102).

Además de tener en cuenta todo esto, se ha de observar también la compensación horaria de acuerdo al número de kilómetros que cada maestro itinerante va a invertir en la realización de los desplazamientos. 
Es la tarea más larga. Generalmente todos los maestros itinerantes y el Jefe de estudios con el Director están presentes y se acuerda el horario con el consentimiento favorable de los presentes.

b) En segundo lugar se configura el horario del Equipo Directivo teniendo en cuenta los momentos que han de reunirse en la cabecera o que han de visitar las localidades que forman el CRA realizando su labor directiva. La normativa al respecto establece que los miembros del Equipo Directivo, de acuerdo al número de unidades de cada colegio y siempre que estén cubiertas las necesidades horarias de su especialidad, han de impartir una cantidad determinada de horas lectivas con alumnos, dedicando el resto del horario a tareas directivas.

En los centros de 6 a 8 unidades, los cargos directivos desempeñan 15 horas lectivas. En centros de 9 a 17 unidades, las horas lectivas son 12. Las horas lectivas en colegios de 18 a 27 unidades son 9, mientras que los cargos directivos impartirán 6 horas lectivas en centros de 28 o más unidades.

c) En tercer lugar el Jefe de estudios y Director se reúnen con los maestros generalistas e itinerantes de cada localidad y se distribuyen las horas lectivas de las diferentes materias, de acuerdo a las características educativas que se encuentran en la localidad durante el curso académico presente: proyectos pedagógicos, posibilidad de apoyos, tiempo dedicado por los especialistas y compartidos, etc. Cada localidad confecciona la totalidad de su horario sabiendo que siempre quedan elementos o franjas horarias sueltas que habrán de ajustarse más tarde.

d) Hay que contar, igualmente, con los maestros compartidos de Logopedia, Orientación, Pedagogía Terapéutica y Religión, ya que en función del tiempo que dediquen al CRA habrá que organizar su trabajo. Ésta es también una labor coordinativa complicada. Suele ocurrir que tras tener elaborado el horario general del centro, éste sufre modificaciones en base a que ha de existir concordancia con las horas que el maestro compartido dedica a otros centros. Por ejemplo, si el maestro de Religión dispone únicamente de los lunes para impartir su materia en una localidad del CRA, esta localidad ha de disponer su horario para que el maestro imparta docencia ese día, condicionando al resto del horario. $\mathrm{O}$ acordar con la especialista en Pedagogía Terapéutica su presencia en el colegio durante la celebración de las sesiones de las materias concretas en las que los alumnos necesitan ayuda. Lo mismo ocurre con el servicio de Logopedia, que al dedicarse a problemas en el lenguaje, no asistirá al centro sino en el horario concreto de enseñanza de la asignatura. Idéntica fórmula precisa el servicio de Orientación. Ello supone observar una perfecta coordinación con esos especialistas.

Además de atender a estos aspectos principales, en el proceso de elaboración del horario de un CRA, también se han de observar otros aspectos que se detaIlan igualmente en las Instrucciones Reguladoras de Escuelas y Colegios (Orden de 29 de febrero de 1996, BOE del 9 de marzo):

- Cuando un maestro no cubre su horario lectivo, pueden serle asignadas otras tareas, relacionadas con: impartición de áreas, sustitución de maestros, atención a alumnos con dificultades de aprendizaje, desdoblamiento de grupos y apoyo a otros maestros. (Punto 77). Este punto es importante para explicar una de las características más valorada en los CRAs. Siempre que sea posible y 
debido a la unión de diferentes niveles en un mismo grupo, se producen desdobles. Consisten en dividir los distintos niveles del grupo, quedando el tutor con un nivel y el maestro que posibilita el desdoble saca del aula a otro $u$ otros niveles para trabajar con ellos. Esta es una de las ocasiones en que la enseñanza en el CRA más se relaja, al realizarse con pocos alumnos y además del mismo nivel o, al menos, sin demasiada diferencia de edad. En el supuesto de que los desdobles no sean posibles, sí que se intentan los apoyos a casos individuales de alumnos que lo necesitan. Generalmente son dentro del aula.

- Cuando se cubran las principales necesidades educativas del centro, puede computárseles a algunos maestros horas para el desempeño de las siguientes funciones: coordinación de ciclos, coordinación de medios informáticos y audiovisuales, responsables de biblioteca y de recursos documentales, representación del centro en el Centro de Profesores y Recursos y organización voluntaria de actividades deportivas y artísticas fuera del horario lectivo. (Punto78).

- Además de las veinticinco horas lectivas, cada maestro ha de dedicar cinco horas semanales en el colegio para la realización, entre otras, de actividades como: entrevistas con padres, programación de actividades de aula, extraescolares y complementarias, asistencia a reuniones del Claustro, de la Comisión de Coordinación Pedagógica, del Consejo Escolar, de los Equipos de Ciclo, actividades de perfeccionamiento e investigación educativa y otras actividades establecidas en la Programación General Anual. (Punto 71).

La elaboración definitiva del horario de un CRA sería imposible sin la presencia de un medio como el teléfono y, actualmente, el correo electrónico, que nos permite un rápido contacto con las personas implicadas o con centros que comparten maestros o entre compañeros para coordinar actuaciones. El uso de estos medios se hace muy significativo en el proceso de enseñanza del medio rural.

\subsection{La relación con las Asociaciones de Padres de Alumnos -APAs- y los Ayunta- mientos}

El Real Decreto 1533/1986, de 11 de julio (BOE del 29), regula la existencia de las Asociaciones de Padres de Alumnos en las Escuelas y Colegios.

En el contenido de este Real Decreto destaca la colaboración y participación de los padres de alumnos en aspectos relacionados con la estructura y organización de los centros educativos y la postura abierta que el colegio ha de presentar para lograr que la participación sea efectiva.

Asimismo, el Título VI del Real Decreto 82/1996, se ocupa de las competencias de estas asociaciones respecto a la dinámica escolar. Elementos como la utilización de las dependencias del centro, la representación en el Consejo Escolar, la presencia en el Proyecto Educativo de Centro, el conocimiento del Proyecto Curricular de etapa, la participación en la gestión del colegio y la elaboración de propuestas didácticas, nos dan una idea del protagonismo de la APA en cualquier tipo de colegio. 
En el medio rural destaca la cercanía existente entre las familias y la escuela. Los pueblos son núcleos pequeños de población que contribuyen a que la comunicación entre maestros, alumnos y familias sea directa y fácil de establecer.

Conscientes de la importancia que la presencia de las APAs atesora, además de las periódicas reuniones entre los tutores y los padres de los alumnos para trabajar conjuntamente en beneficio de la educación, cualquier Colegio Rural Agrupado puede establecer una línea de actuación que refuerce las relaciones entre el centro y las familias, para el buen funcionamiento del colegio.

En el CRA San Vicente de la Sonsierrra, el Equipo Directivo mantiene reuniones bimensuales con representantes de la Asociación de Padres de Alumnos de cada localidad. En estas sesiones se establecen los criterios para la realización de proyectos comunes en todas las escuelas del CRA. Se tratan igualmente temas referentes a las necesidades de cada localidad, actuaciones con los Ayuntamientos, sugerencias, preparación de actividades extraescolares, etc.

Estas reuniones permiten al Equipo Directivo coordinar mucho mejor los proyectos del CRA que requieren la participación conjunta con familias y Ayuntamientos.

Con la intención de fomentar la mentalidad de centro único -asignatura pendiente de la Comunidad Educativa de los CRAs-, elaboramos un Boletín Informativo para Familias, en donde damos a conocer los maestros que trabajan en el CRA, la distribución de aulas, el Consejo Escolar, normas de convivencia del centro, horarios y calendario anual, actividades del colegio y de las APAs, información histórica de nuestro CRA y, en definitiva, cualquier aspecto que beneficie el funcionamiento conjunto de la Comunidad Educativa.

Igualmente, se ofrece un Resumen para Familias del Proyecto Educativo del Centro a la familia de cada nuevo alumno que se matricula. En él se describen las notas de identidad y los aspectos más representativos del CRA que la familia tendrá en cuenta durante todo el período de escolarización de su hijo o hija.

En la secretaría del centro se encuentran los documentos a los que la APA puede tener acceso, si bien cada Asociación de Padres cuenta con una copia del PEC del Colegio Rural Agrupado.

Los Ayuntamientos, como ocurre con las APAs, son entidades cercanas a la escuela en el medio rural.

La participación de este organismo en la vida educativa del CRA se concreta en dos actuaciones:

1. Su presencia en el Consejo Escolar del centro.

Como señalamos en el apartado dedicado al Consejo Escolar, un representante del Ayuntamiento -cada año se turnan las localidades-, ha de asistir a las reuniones e informar debidamente al resto de Ayuntamientos del CRA de los asuntos debatidos y de los acuerdos adoptados.

2. La obligación de mantener en óptimas condiciones las instalaciones del colegio de la localidad.

Este aspecto se torna familiar en el medio rural. Con una visita al Ayuntamiento se pueden tratar temas educativos directamente con el Alcalde de la localidad 
o contar con la presencia de concejales o alguaciles en las dependencias del centro a cualquier hora del día.

Estas posibilidades condicionan positivamente el posterior desarrollo de proyectos comunes.

De todas formas, es este organismo de la comunidad educativa quien menos participa, a nuestro entender, de la mentalidad asociativa entre localidades que requiere un Colegio Rural Agrupado. Sí que existe una lógica preocupación por la enseñanza escolar, pero su interés por el CRA acaba en la escuela de la localidad determinada. Cada Ayuntamiento tiene suficiente con el pueblo al que representa, como para involucrarse con otras localidades vecinas con las que, posiblemente, habrá tenido algún conato en el tiempo y asumido unas costumbres ya establecidas con anterioridad al origen del CRA. El Equipo Directivo se ve obligado a conocer las características de cada Ayuntamiento y de acuerdo a ellas relacionarse.

\subsection{Recursos materiales, económicos y de formación docente que posibilitan el funcionamiento de los CRAs}

En este apartado hablaremos de dos organismos importantes en la vida educativa de los Colegios Rurales Agrupados: la Administración Educativa y el Centro de Profesores y Recursos de la zona -C.P.R.-.

La mayor parte de los recursos materiales llegan desde la Administración Educativa ahora con plenas competencias en La Rioja y antes gestionada desde el Ministerio de Educación y Ciencia. Los recursos materiales de un CRA, aunque no sean tan escasos como la gente opina, resultan de difícil manejo. Es bien sabida la necesidad de transportar de una localidad a otra el material que dispone el centro. Los itinerantes y el Equipo Directivo son los principales encargados de esta labor. También las reuniones quincenales de coordinación son aprovechadas para el intercambio de material. Ello obliga a coordinar el tiempo de empleo de un mismo material por los tutores de un mismo ciclo, pero de diferentes localidades.

Aunque el transporte es la solución más factible, existen materiales llegados al CRA que obligan a su establecimiento en una localidad determinada. Un equipo de música, por ejemplo, no puede ser desplazado constantemente. En tales casos, se estudian las necesidades de cada localidad o el proyecto de uso más adecuado y de acuerdo a ello se destina el material a una escuela determinada.

En otras ocasiones la concesión de material viene desglosada por localidades, ya que la petición desde el centro también fue realizada de igual manera.

La tendencia es ir dotando a cada colegio del CRA lo suficientemente bien como para tener que transportar la menor cantidad de materiales posible. Otra solución, como ocurre en el CRA San Vicente de la Sonsierrra, es establecer dos sedes de material y desde ellas desplazarlo a la localidad más cercana.

En cuanto a los recursos económicos con los que cuenta el centro, diremos que éste recibe, a lo largo del año, el ingreso de las partidas de dinero que le corresponden de acuerdo a sus características. La utilización de ese dinero por parte de los órganos responsables del centro ha de atenerse a lo expuesto en la Orden de 23 de 
septiembre de 1999 (BOE del 1 de octubre), por la que se desarrolla el Real Decreto 2723/1998, de 18 de diciembre, por el que se regula la autonomía en la gestión económica de los centros docentes públicos no universitarios. Ahora bien, la Ley Orgánica 9/1995, de 20 de noviembre, (BOE del 21), de la participación, la evaluación y el gobierno de los centros docentes (LOPEG) otorga, en su Artículo 7, la autonomía en la gestión de los recursos económicos en los centros públicos, a la normativa propia de cada Administración Educativa. Es por ello que la Orden mencionada, una vez que las provincias españolas van asumiendo competencias educativas, ha de ser estudiada y aprobada para su puesta en funcionamiento particularmente en cada comunidad. La Rioja se encuentra en esta fase.

Todos los pasos económicos son controlados por la Administración Educativa. La normativa tiende a una mayor independencia en la actuación de los órganos de gestión económica. A grandes rasgos, podemos decir que el Consejo Escolar es el órgano encargado de aprobar el proyecto de presupuesto del centro y realizar su seguimiento. El Director es el máximo responsable de la gestión de los recursos económicos del centro.

Un CRA ha de atender a los gastos fijos de mantenimiento antes de repartir dinero entre las diferentes localidades, normalmente de acuerdo al número de maestros, de niños y de unidades por localidad.

Al hablar de los recursos de formación docente habremos de referirnos a la Orden de 18 de marzo de 1996 (BOE del 26), por la que se desarrolla y aplica el Real Decreto $1693 / 1995$, de 20 de octubre, por el que se regula la creación y el funcionamiento de los Centros de Profesores y Recursos -CPR-, encargados de facilitar, en lo posible, ayuda material y formativa a los centros.

Este Real Decreto supuso la integración de los Centros de Profesores (creados anteriormente a la implantación de la Reforma Educativa, para la formación permanente del profesorado en su ámbito de gestión) y de los Centros de Recursos (basados en el apoyo a la tarea docente en las zonas rurales caracterizadas por la dispersión de las unidades escolares). Una vez creados los Colegios Rurales Agrupados, se inició el proceso de unificación de ambos centros formativos, para permitir una atención más cercana a los colegios educativos.

Los objetivos con los que nacen los CPRs vienen a significar aspectos como: desarrollar la formación permanente del profesorado, promover la investigación y la innovación educativa y la difusión y el intercambio de experiencias pedagógicas y didácticas, asesorar a los centros sobre la utilización de materiales que apoyen el desarrollo del currículo y participar en actividades de dinamización social y cultural en unión con los colegios.

Todos los CPRs disponen de una plantilla de asesores que deben planificar y desarrollar la oferta de actividades del plan de actuación de ese CPR. Estos maestros asesores han de atender, en la medida de sus posibilidades, aquellas demandas formativas y de material de los colegios que su ámbito de competencias determine. Ejemplo de ello sería su colaboración en la reciente puesta en marcha del aula de informática de cada escuela de los CRAs de La Rioja, tras la dotación de equipos que el MEC, a través del Proyecto Aldea Digital, dispuso en los Centros Rurales Agrupados de nuestra comunidad durante el pasado año. También fueron estos asesores quie- 
nes se encargaron de la labor formativa de los maestros en los aspectos informáticos de aplicación al aula. Todos los CPRs de La Rioja -Nájera, Logroño, Calahorra y Cervera- participaron en este proyecto de informatización del medio rural.

En el CRA existe un representante del centro en el CPR, al que corresponderían, principalmente, las funciones de:

- Informar a los maestros de las actividades de formación programadas por el CPR.

- Facilitar la comunicación entre el CPR y el centro, motivando a los compañeros para la realización de proyectos y creación de Seminarios y Grupos de Trabajo.

- Planificar y diseñar, en coordinación con otros representantes, actividades que respondan a las demandas de formación del profesorado.

- Acercar los recursos didácticos del CPR al centro. Actividad de gran utilidad para un CRA necesitado, especialmente, de recursos materiales. El CPR se convierte en un centro proveedor.

\subsection{Actividades complementarias y extraescolares en el CRA}

El Centro Rural de Innovación Educativa -CRIE-.

Las Instrucciones que regulan la Organización y el Funcionamiento de las Escuelas y Colegios (Orden de 29 de febrero de 1996, BOE del 9 de marzo), se refieren al programa anual de actividades complementarias y extraescolares como a un proyecto común, elaborado por el Equipo Directivo, atendiendo las propuestas del Claustro, de los Equipos de Ciclo y de los representantes de los padres de alumnos y bajo la aprobación del Consejo Escolar.

Estas actividades tienen un carácter voluntario para alumnos y maestros.

Atendiendo a ello, podemos decir que un CRA está en disposición de realizar la mayor parte de actividades que cualquier otro centro no rural realiza. Sin embargo, hay que señalar que un CRA está "obligado" a la planificación de actividades conjuntas que estimulen y motiven la convivencia entre los maestros, los alumnos, las familias y los Ayuntamientos de las diferentes localidades que forman el colegio rural.

No es posible que un tutor programe una actividad fuera de la localidad para su tutoría exclusivamente. Se requiere haber acordado con el Equipo de Ciclo correspondiente la actividad concreta, pensada para todos los alumnos del ciclo y, por lo tanto, de todas las localidades del CRA. Sí nos parece posible programar actividades dentro de la localidad para una única tutoría.

Existen a lo largo del año varias actividades, generalmente comunes a todos los CRAs, en las que la comunidad educativa entera se ve implicada y animada a participar: carnaval, las salidas fuera de las localidades del CRA, en las que se hace necesario contratar medios de transporte, viaje de estudios, si lo hubiere, y una convivencia final al terminar el curso académico. Estas actividades conllevan la convivencia de todos los niños en la cabecera del CRA o en la localidad establecida por turno. En el CRA San Vicente de la Sonsierra, con el objetivo de que los alumnos conozcan todos los pueblos que forman el centro, la fiesta final de convivencia se viene realizando cada año en una localidad diferente del CRA. 
En este apartado de actividades complementarias es necesario hacer referencia a una actividad exclusiva de estos centros rurales. Nos referimos a las convivencias en los CRIEs -Centros Rurales de Innovación Educativa-.

La Orden de 29 de abril de 1996 (BOE del 11 de mayo), de creación y funcionamiento de los Centros Rurales de Innovación Educativa, en su Apartado Exposición de Motivos matiza que la implantación generalizada del modelo de Colegios Rurales Agrupados requiere una reorganización de los servicios de apoyo externo. Las diferentes medidas que se han Ilevado a cabo para mejorar la oferta educativa hacia los alumnos de las escuelas rurales, han posibilitado la aparición de los Centros Rurales de Innovación Educativa. Su acción está dirigida prioritariamente a los centros incompletos de Educación Infantil y Primaria y a los CRAs. Estos centros, a través de las convivencias periódicas de alumnos de diferentes zonas y escuelas rurales, han tenido como objetivos prioritarios:

- Contribuir a la mejora del desarrollo personal y de socialización de los alumnos.

- Realizar, con la colaboración de los maestros de los colegios rurales, actividades complementarias a las que se hacen en estos colegios y que refuercen el currículo escolar.

- Fomentar la realización de actividades de innovación curricular y de formación del profesorado, con el objetivo de mejorar la calidad educativa del medio rural.

- Impulsar, en coordinación con los colegios, actividades cooperativas que refuercen la unión y el trabajo de la comunidad educativa y el incremento de la participación de las familias en el ámbito escolar.

La Administración Educativa de cada autonomía planifica la actuación del CRIE dentro de su competencia territorial, realizando una convocatoria pública en la que se exponga el calendario de convivencias, las condiciones de participación y los criterios de selección de los grupos de alumnos y de centros.

En La Rioja, el Centro Rural de Innovación Educativa -CRIER- fue legalmente creado en virtud de la Orden Ministerial de 29 de abril de 1996 y desde entonces se llevan organizando dos semanas de convivencias anuales entre los alumnos del tercer ciclo de Educación Primaria de los diferentes CRAs de la comunidad.

Si bien cada Colegio Rural Agrupado manifiesta unas peculiaridades concretas, creemos que lo aquí expuesto ofrece una visión general sobre la que se sustenta su organización, estructura y funcionamiento.

\section{Consideraciones finales}

Una vez estudiado ampliamente el marco legislativo actual que rige la vida educativa de los Colegios Rurales Agrupados en cuanto a la organización y estructura que estos centros desarrollan, a nivel general y contextualizado en el ejemplo del CRA San Vicente de la Sonsierra de La Rioja, se ofrece, a continuación, la realidad que envuelve a estos centros una vez transcurrido varios años desde su puesta en marcha y contando con los indicadores suficientes para expresar aportaciones al respecto. 
Las conclusiones obtenidas de estudios ${ }^{2}$, investigaciones ${ }^{3}$ y jornadas ${ }^{4}$ realizadas en torno a los CRAs en distintas zonas del territorio español, tienen una gran similitud a la hora de confluir en los aspectos que han de ser destacados en la realidad educativa de los Colegios Rurales Agrupados y que se pasan a describir.

Respecto al marco legislativo

> El marco legislativo que sirvió para la creación y puesta en marcha de los Colegios Rurales Agrupados se originó en 1986, bajo el amparo de la entonces Ley General de Educación de 1970 -LGE-, mientras que su desarrollo coincidió, en ciertas zonas, con la implantación progresiva de la Ley Orgánica de Ordenación General del Sistema Educativo de 1990 -LOGSE-; de manera que durante un tiempo convivieron ambos Sistemas Educativos -LGE y LOGSE-.

> Las particulares características que introdujo la Ley Orgánica de Ordenación General del Sistema Educativo de 1990 -LOGSE-, como la creación de nuevas especialidades, la ratio profesor/alumno, PEC y PC, Equipos de Gobierno, de Coordinación, nuevos Ciclos, Etapas, etc. demandaban, entonces, nuevas orientaciones para su contextualización y adaptación a las características de los Colegios Rurales Agrupados.

Actualmente la normativa sobre la que se basa la organización y estructura de los CRAs es común a la de los colegios rurales y urbanos, dándose un vacío legal para el desarrollo de la Educación en los Colegios Rurales Agrupados, sabiendo que las características de éstos son muy diferentes a las del resto de centros, lo que hace que se agudicen ciertos problemas, exclusivos de este tipo de centros.

Respecto a los alumnos

$>$ El aula o las aulas de un centro completo, bien sea rural o urbano, donde los alumnos se agrupan por niveles o edades, nada tiene que ver con el aula de un Colegio Rural Agrupado que acoge y educa a alumnos de diversos niveles y/o edades; por ello debe tenerse diferentes consideraciones para este tipo de centros, en cuanto a ratio, apoyos personales, recursos materiales, horarios, etc.

> Un Colegio Rural Agrupado formado por diferentes localidades ofrece escasas oportunidades de convivencia entre todos los alumnos que forman el CRA.

\section{Respecto al profesorado}

$>$ Las características del medio rural hacen que los maestros vean este entorno como un paso previo a su definitivo asentamiento en el medio urbano, por lo

2. Como el de Hervás, $M^{a}$ José (1993). Castilla y León. Una alternativa para la escuela en el medio rural, en Cuadernos de Pedagogía no 211. Febrero 1993, pp. 44-49.

3. Como el de Palomares Aguirre, $M^{a}$ Carmen (2000). Variables que condicionan la satisfacción de los profesores que trabajan en Colegios Rurales Agrupados, en Bordón, $n^{\circ} 52$ (2), pp. 213-227.

4. Como las VI Jornadas Provinciales de Escuela Rural. Segura de la Sierra (Jaén). Mayo de 1995. Las I Jornadas sobre Colegios Públicos Rurales de Andalucía. Alcalá La Real (Jaén) Septiembre de 1998. Las I Jornadas Universidad-Escuela. La Escuela Rural, primer paso al mundo docente que organizó la Universidad de La Rioja durante el curso 1999/00. 
que las plantillas de los CRAs tienden a ser inestables y de constante movilidad. Esto va a impedir consolidar equipos de trabajo estables que elaboren, asuman y desarrollen Proyectos Educativos Pedagógicos y de Innovación.

> Los maestros itinerantes han de disponer de un vehículo propio al servicio de la Administración Educativa, pues los desplazamientos para ejercer su docencia obligan a ello.

$>$ Uno de los criterios de calidad educativa existente en los centros viene ofrecida por la satisfacción personal y la valoración que los profesores hacen de su trabajo. Se han realizado numerosos estudios con respecto a este punto. Palomares (2000), al indagar sobre las variables que condicionan la satisfacción de los profesores que trabajan en Colegios Rurales Agrupados de la provincia de Cuenca, constata que los profesores de zonas rurales consideran que su trabajo no está bien considerado, ni bien remunerado, ni es un trabajo llevadero. A pesar de estas apreciaciones, estos Maestros encuestados se muestran bastante satisfechos con su profesión observando que es la vocación el motor de su profesionalidad.

Entre otras aportaciones, esta autora, en su investigación a partir de una encuesta a 118 profesores que ejercen en las zonas rurales de la provincia de Cuenca, destaca que en opinión de los Maestros:

- La constitución de los CRAs hace que los padres y la Comunidad Educativa valoren más la tarea de enseñar reportando más ventajas que inconvenientes.

- Más del 70\% apoyan la constitución de los CRAs como organización educativa tipo, para las zonas poco habitadas de la provincia de Cuenca, ya que mejora su implicación en el aula $(88,21 \%)$, permite intercambiar experiencias educativas $(79,40 \%)$, facilita la comunicación y colaboración con los padres $(64,70 \%)$ y permite superar el aislamiento del profesorado $(85,28 \%)$.

- Han mejorado los aspectos didácticos del centro que favorecen situaciones de calidad educativa (experiencias, colaboración e implicación) y sobre todo sirve para superar el aislamiento personal y profesional de los docentes.

- La experiencia, al trabajar en un centro rural, es más positiva para los alumnos y para las zonas rurales y en menor medida para los profesores y las familias.

- Antes de generalizar la experiencia de los CRAs a todas las zonas rurales, es conveniente estudiarla detalladamente, informar y consultar con los profesionales implicados, así como con la Comunidad Educativa, la conveniencia o no de iniciar la constitución de un Colegio Rural Agrupado. Finaliza Palomares (2000) con la reflexión de que "los Colegios Rurales Agrupados constituyen un tipo de organización docente para las zonas rurales que genera condiciones de calidad educativa y favorece la compensación de desigualdades, son por tanto organizaciones de centro que no deben ni pueden ser impuestos directamente desde la Administración. Con el sistema impositivo se puede no llegar a alcanzar los objetivos que se persiguen para el medio rural. Los colegios Rurales Agrupados deben de ser creados, potenciados y puestos en funcionamiento, siempre que se tenga en consideración la historia, la cul- 
tura y las necesidades educativas de la 'zona comarcal' en la que piensan constituirse" (p. 221).

\section{Respecto a las APAs y Ayuntamientos}

- Abundantes estudios sociológicos acerca de las áreas rurales y urbanas coinciden en afirmar que el movimiento migratorio hacia la ciudad es provocado por la falta de calidad de vida en el medio rural. Ello es también vinculante a la escuela, ya que la masificación que se produce en los colegios urbanos es debida, en parte, a que las familias de los pueblos optan por establecerse en la ciudad. El mayor cuidado en la calidad de vida rural: servicios, cultura, economía, ocio, educación, etc., beneficiaría el asentamiento definitivo de las familias en los pueblos, con su aporte positivo a la calidad de las escuelas rurales.

> Las características socio-educativas de los CRAs demandan que todos los miembros de la Comunidad Educativa funcionen con una mentalidad única, en pos de los mismos intereses. Ésta sigue siendo la asignatura pendiente de estos centros.

> Algunas localidades de los CRAs no cuentan con Asociaciones de Padres con el consiguiente deterioro de su representación y participación en la Comunidad Educativa.

- Actuación independiente de cada Ayuntamiento, al no asumir la pertenencia de la localidad a un centro educativo único con intereses comunes.

Corbeira Novo (1999) en su estudio sobre las vinculaciones de un programa de Educación Compensatoria con los Centros de Recursos y los Colegios Rurales Agrupados y tras haber realizado una encuesta a 117 padres de hijos escolarizados en un CRA, llega a las siguientes conclusiones donde se aprecia una valoración positiva hacia este tipo de centros:

- La totalidad de los padres encuestados considera que el CRA es un buen método de escolarización para sus hijos.

- Ofrece la posibilidad de mantener a sus hijos cerca de casa y de la familia.

- En líneas generales consideran que las relaciones sociales de sus hijos se encuentran cubiertas en el CRA pero se ven favorecidas en el momento que los niños lo abandonan para asistir a los Institutos.

- Los padres están plenamente convencidos de que el grado de mejoría en lo que respecta a las instalaciones educativas, los materiales didácticos, el profesorado, la calidad de la enseñanza y las relaciones sociales que se establecen entre los diferentes colectivos que intervienen en el proceso educativo (profesores, alumnos y padres) son notorias al formarse los CRAs.

Respecto a la calidad educativa de los centros

> La dotación de maestros en los CRAs se rige por el número de unidades y de alumnos y no por las verdaderas necesidades pedagógicas del centro. La escuela rural debería contar con una especial atención en la designación de recursos humanos, tanto de apoyo, como de generalistas y especialistas. 
$>$ La distancia entre localidades, con el tipo de carreteras que las separan (que no son ni con mucho las de cinturón de la capital) viene siendo un impedimento en la satisfacción para el desarrollo de la tarea educativa de los maestros itinerantes .

$>$ La Coordinación docente es uno de los grandes inconvenientes de los CRAs. En las I Jornadas sobre Colegios Públicos Rurales de Andalucía se plantearon las cuestiones que podrían dar lugar a problemas en la Coordinación de los Equipos Docentes de Ciclo, advirtiendo que:

- los profesores cuentan con varios Ciclos,

- los desplazamientos aminoran los períodos de reunión,

- resulta difícil conjugar los diferentes intereses de cada localidad,

- los maestros sólo conocen a los alumnos de la localidad donde ejercen su profesión,

- un excesivo número de maestros viven fuera del agrupamiento,

- existen demasiados temas para ser tratados en una única sesión de Coordinación,

- falta de tiempo real para las reuniones de los distintos Órganos de Coordinación Docente (Equipos de Ciclo y Comisión de Coordinación Pedagógica).

> La Sede o cabecera del CRA, al ser el núcleo administrativo, es también la localidad que obtiene un mayor beneficio respecto a los otras que forman el Centro Rural Agrupado.

\section{Algunas medidas de actuación}

Tras estas reflexiones y consideraciones que ofrecen la compleja problemática de los CRAs, mostramos algunas de las medidas de actuación, integrando las que Juan M. Prieto Tellado recogió en las I Jornadas sobre Colegios Públicos Rurales de Andalucía, que pudieran paliar estas dificultades dotando así a los CRAs de una mayor calidad educativa.

- Elaborar Proyectos Pedagógicos comunes, consensuados y asumidos por toda la Comunidad Educativa.

- Adaptar el modelo organizativo de los Centros a las características del Colegio Rural Agrupado adoptando nuevas fórmulas y respetando los acuerdos internos que se tomen en los Órganos de Gobierno que rigen el centro.

- Potenciar la fortaleza organizativa disponiendo de Equipos Directivos completos y Órganos Colegiados.

- Crear centros de Educación Permanente de adultos en los distintos pueblos que puedan ser foco dinamizador de cultura, que permitan la alfabetización de los mayores y la recuperación educativa de aquellos alumnos que, por todas las deficiencias señaladas, no hubieran alcanzado la titulación académica básica. Estos centros deberían estar coordinados con las escuelas rurales para promover algunas actividades culturales en los pueblos. 
- Mejorar las instalaciones escolares y el equipamiento de estos centros dotándoles de aulas-laboratorio, biblioteca, salas de motricidad, etc. e incrementando los recursos materiales.

- Modificar el concepto de ratio -profesor-alumno- teniendo en cuenta variables diferentes al número de alumnos.

- Facilitar la Coordinación docente modificando las jornadas lectivas actuales.

- Potenciar las posibilidades de trabajo de los Centros de Profesores y Recursos -CPR- en el medio rural, con convocatorias de Jornadas de la Educación Rural. Cada Comunidad Autónoma o provincia podría reflexionar y profundizar en la problemática y mejora de la calidad educativa de sus centros rurales; ejemplo de ello son las Actas de la VI Jornadas provinciales de escuela rural del CPR de Segura de la Sierra -Jaén- (1995) dedicadas al tratamiento de la diversidad en las Escuelas Rurales.

- Favorecer iniciativas y experiencias de convivencia como las de los Centros Rurales de Innovación Educativa -CRIE-.

- Aumentar los recursos y las plantillas a partir de un análisis de las necesidades previas a la constitución de los CRAs.

- Mejorar la situación laboral, profesional, económica, social y cultural del profesorado a través de:

- Acondicionamiento de las viviendas de Maestros en los núcleos rurales.

- Regulación jurídica del profesorado itinerante, así como del tiempo de traslados a los distintos pueblos, que actualmente se hace en función de los Kms pero no se tiene en cuenta el estado de las carreteras en estos medios rurales.

- Aumento de la puntuación a efectos de méritos para la promoción y concursos de traslados y considerar la docencia en los CRAs como puestos de difícil desempeño.

- Mayor facilidad para su perfeccionamiento.

- Replantear si la estructura actual de los CRAs mejora la calidad educativa del medio rural o si son necesarios algunos cambios, tras la asunción de las plenas competencias educativas por parte de las diferentes Autonomías.

- Incrementar la atención, interés y conocimiento por la tarea docente desarrollada en estos centros desde la Formación Inicial del Profesorado.

Respecto a este último punto hemos de poner de manifiesto la iniciativa llevada a cabo en el curso 1999/00 por la Coordinación del Prácticum de la Titulación de Maestro de la Universidad de La Rioja, a la cual dedicamos el siguiente apartado.

\section{Los colegios rurales agrupados en la formación inicial del profesorado de la Uni- versidad de La Rioja}

La Planificación, organización y diseño de las prácticas escolares de la Titulación de Maestro en la Universidad de La Rioja es tarea de la Coordinación, nombrada por el Vicerrectorado de Ordenación Académica, y tiene una doble función: la Formación para el Prácticum y la Coordinación del Prácticum. 
La función de formación para el prácticum pretende:

- Acercar la realidad escolar a la Universidad y sobre todo a los alumnos de tercer curso de la Titulación de Maestro.

- Orientar para el proceso didáctico-reflexivo inherente a las prácticas escolares: objetivos, trabajo de campo, memoria, evaluación, etc.

- Unificar criterios para el desarrollo y evaluación del prácticum entre todo el personal involucrado en las prácticas escolares -Maestros-Tutores de los centros de Primaria e Infantil y Profesores-Tutores de la Universidad-.

Todo ello a través de seminarios formativos, jornadas y debates contando con la colaboración de los principales protagonistas, los propios maestros de los centros escolares.

La función de coordinación comprende la organización, planificación y elaboración del Plan de prácticas anual, el contacto con los centros para la obtención de puestos para la realización de las prácticas, establecer los criterios para su seguimiento y evaluación, la distribución de alumnos en los distintos centros, la coordinación de los Maestros-Tutores y Profesores-Tutores de la Universidad, así como resolver cuantas cuestiones y problemas pudieran surgir en el desarrollo del Prácticum.

Las Coordinadoras de prácticas de la Titulación de Maestro de la Universidad de La Rioja vienen observando, desde hace años, que las preferencias de los alumnos al elegir centro para sus prácticas, se dirigen a Logroño capital o cabeceras de comarca de La Rioja y se estima que deben ampliar sus horizontes y conocer el medio rural que posiblemente sea para muchos de ellos el lugar donde desarrollarán su trabajo como primer destino, si estos alumnos optan profesionalmente por la función pública docente. Por otra parte la organización escolar y el trabajo que se desarrolla en los Centros Rurales Agrupados conlleva una estructura y organización bien diferente a la de los centros urbanos, puesto que un maestro o maestra generalista asiste a varios niveles en una misma clase o un maestro o maestra especialista lo comparten varias localidades.

Por éstas y otras razones la Coordinación de prácticas, dentro de la función de formación para el Prácticum, consideró de interés dedicar en el curso 1999/2000 unas Jornadas que dieran a conocer la problemática particular de estos Centros Rurales Agrupados desde la experiencia de sus profesores así como las diferentes iniciativas educativas que se están llevando a cabo en estos centros de la Comunidad Autónoma de La Rioja. Por otra parte, la Universidad de La Rioja, desde años, viene interesándose por las salidas profesionales de sus alumnos, es por ello, que en estas Jornadas también se plantease el sistema de acceso a la función pública docente para los Diplomados de la Titulación de Maestro.

Durante los meses de octubre-noviembre y con una duración de 20 horas, se desarrollaron las "I Jornadas Universidad-Escuela. La escuela rural primer paso al mundo

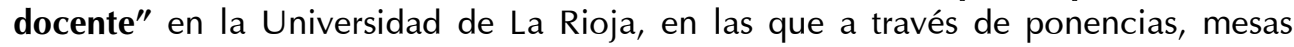
redondas y debates se ofrecieron cuatro grandes bloques de contenido:

1. Los Centros Rurales Agrupados de Primaria e Infantil.

2. Innovación e investigación en la Escuela. Iniciativas educativas en la Comunidad Autónoma de La Rioja. 
3. Acceso a la función pública docente -Oposiciones de Magisterio- .

4. Preparación para unas prácticas escolares reflexivas.

Para los tres primeros bloques se contó con la colaboración de maestros y maestras en ejercicio que ofrecieron la realidad escolar a través de sus experiencias, siendo el cuarto dinamizado por la Coordinación de Prácticas.

Estas I Jornadas Universidad-Escuela. La escuela Rural primer paso al mundo docente despertaron un gran interés si atendemos al elevado número de participantes que asistieron a las ponencias y mesas redondas organizadas, así como por el fruto que las experiencias allí expuestas ofrecieron a los alumnos universitarios, quienes incluso reclamaron de los ponentes nuevas colaboraciones para la realización de sus trabajos curriculares.

Es nuestra labor como formadores de Maestros ilusionar a la Universidad de La Rioja y a otras universidades a fomentar este tipo de acciones de acercamiento a la escuela rural, pues es en este contexto escolar donde la educación se torna enormente viva, fresca y humanamente próxima.

Por todo ello, la educación en el medio rural merece estar presente en los estudios de la Titulación de Maestros, pues recordemos que, con toda probabilidad, será en un Colegio Rural Agrupado donde inicien el desempeño de su labor educativa.

Este tipo de actuaciones en la formación inicial del Maestro posibilitan momentos de contacto real y directo con docentes que conocen ampliamente el medio rural, dispuestos a ofrecer su experiencia práctica. La Universidad ha de aprovechar esta oportunidad para brindársela a sus alumnos.

\section{Referencias bibliográficas y legislativas}

Indicamos el marco legislativo del territorio M.E.C. y de la Comunidad Autónoma de la Rioja utilizado en la realización de este artículo, añadiendo otras disposiciones relacionadas con los Colegios Rurales Agrupados.

CENTRO DE PROFESORES Y RECURSOS -CPR- SEGURA DE LA SIERRA. (1995) Actas de las VI Jornadas provinciales de Escuela Rural. Jaén: Junta de Andalucía y CPR de Segura de la Sierra. Orcera.

COLECTIVO IOE (1987). Guía de recursos comunitarios en el mundo rural. Madrid: Popular.

CORBEIRA NOVO, Manuel (1999). El programa de Educación Compensatoria: sus vinculaciones con los Centros de Recursos y los Colegios Rurales Agrupados, en Innovación Educativa no 9. Pp.171-180.

HERVÁS, Ma José (1993) Castilla y León. Una alternativa para la escuela en el medio rural, en Cuadernos de Pedagogía no 211. Febrero 1993 pp. 44-49.

LEY 14/1970, de 4 de agosto, (BOE 187/70 del 6) General de Educación y Financiamiento de la reforma educativa -LGE-.

LEY ORGÁNICA 8/1985, de 3 de julio (BOE 149/85 del 4) reguladora del Derecho a la Educación -LODE-. 
LEY ORGÁNICA 1/ 1990, de 3 de octubre (BOE del 4) de Ordenación General del Sistema Educativo -LOGSE-.

LEY ORGÁNICA 9/1995, de 20 de noviembre (BOE del 21), de la Participación, la Evaluación y el Gobierno de los centros docentes -LOPEG-.

ORDEN de 20 de julio de 1987 (BOE del 25), por la que se establece el procedimiento para la constitución de Colegios Rurales Agrupados de Educación General Básica.

ORDEN de 21 de junio de 1993 (BOE del 23) por la que se establece el procedimiento de adscripción de los Maestros con destino definitivo en los casos de constitución de Colegios Rurales Agrupados de Educación Infantil y Primaria.

ORDEN de 29 de febrero de 1996 (BOE del 9 de marzo), por las que se aprueban las Instrucciones que regulan la Organización y Funcionamiento de las Escuelas de Educación Infantil y Colegios de Educación Primaria y de los Institutos de Educación Secundaria.

ORDEN de 18 de marzo de 1996 (BOE del 26), por la que se desarrolla y aplica el Real Decreto 1693/1995, de 20 de octubre, por el que se regula la creación y el funcionamiento de los Centros de Profesores y de Recursos.

ORDEN de 29 de abril de 1996 (BOE del 11 de mayo), de creación y funcionamiento de los Centros Rurales de Innovación Educativa.

ORDEN de 23 de septiembre de 1999 (BOE del 1 de octubre), por la que se desarroIla el Real Decreto 2723/1998, de 18 de diciembre, por el que se regula la autonomía en la gestión económica de los centros docentes públicos no universitarios.

PALOMARES AGUIRRE, Ma Carmen (2000). Variables que condicionan la satisfacción de los profesores que trabajan en Colegios Rurales Agrupados, en Bordón no 52 (2) pp.213-227.

REAL DECRETO 1533/1986 de 11 de julio (BOE del 29), por el que se regulan las Asociaciones de Padres de Alumnos.

REAL DECRETO 2731/1986 de 24 de diciembre (BOE del 9 de enero), sobre constitución de Colegios Rurales Agrupados de Educación General Básica.

REAL DECRETO 1440/1991, de 30 de agosto (BOE del 11 de octubre), por el que se establece el título universitario oficial de Maestro, en sus diversas especialidades y las directrices generales propias de los planes de estudio conducentes a su obtención.

REAL DECRETO 82/1996, de 26 de enero (BOE del 20 de febrero), por el que se aprueba el Reglamento Orgánico de las Escuelas de Educación Infantil y de los Colegios de Educación Primaria.

REAL DECRETO 33/1997, de 20 de junio (BOR del 1 de julio), sobre indemnizaciones por razón del servicio al personal de la Comunidad Autónoma de La Rioja.

RESOLUCIÓN 3303 de 19 de octubre de 1999 (BOR del 18 de noviembre), por la que se dictan las instrucciones para la renovación o, en su caso, elección y constitución de los Consejos Escolares de los colegios públicos de Educación Infantil y Educación Primaria de la Comunidad Autónoma de La Rioja. 